\title{
Differential diagnosis of thrombocytopenia in pregnancy
}

\author{
Cesar H. Gutiérrez-Aguirre* and Alejandra C. Esparza-Sandoval \\ Hematology Service "Dr. Jose Eleuterio Gonzalez" University Hospital, Autonomous University of Nuevo Leon, Monterrey, Nuevo Leon, Mexico
}

\begin{abstract}
Thrombocytopenia is encountered in $7-12 \%$ of all pregnancies and is the second most common abnormality of the complete blood count after anemia. The most important causes of thrombocytopenia during pregnancy are gestational thrombocytopenia, accounting for $60-75 \%$ of the cases, which usually poses no risk to either the mother or the product and no treatment is necessary. Furthermore, thrombocytopenia associated with pre-eclampsia, eclampsia, or hemolysis, elevated liver enzymes, and low platelet syndrome in $21 \%$ of the cases, which needs to be detected early due to the urgent medical attention required since the definitive treatment is the delivery of the fetus, and immune thrombocytopenia (ITP) in 3-10\% that has a more severe presentation and can trigger maternal and neonatal complications. The differential diagnosis of the thrombocytopenia is highly important, as the complications and required treatment vary from one disease to another, and necessary to improve maternal and neonatal prognosis.
\end{abstract}

Key words: Thrombocytopenia. Pregnancy. Pre-eclampsia. Hemolysis, elevated liver enzymes, and low platelet syndrome. Gestational.

\section{Introduction}

Platelets are of significant importance in the formation of thrombus since they begin the primary hemostasis. Normal platelet count values range between $150,000 / \mu \mathrm{l}$ and $450,000 / \mu \mathrm{l}$. Thrombocytopenia is defined as a platelet count lower than $150,000 / \mu l$, classified as mild when the platelet count is between 100,000 and $150,000 / \mu \mathrm{l}$, moderate when it is between $50,000 / \mu \mathrm{l}$ and $100,000 / \mu \mathrm{l}$, and severe when the count is below $50,000 /$ l. Thrombocytopenia is considered clinically significant when the platelet count is lower than $100,000 / \mu \mathrm{l}$; furthermore, spontaneous bleeding may occur when the count is lower than $30,000 / \mu 1^{1}$. Nevertheless, even with a normal or close-to-normal platelet count, if there is a quick descent of more than $50 \%$, the cause ought to be investigated ${ }^{2}$.
Thrombocytopenia can occur through different mechanisms such as the lowering of platelet production, an increase in their destruction or other causes such as splenic sequestration or dilution (Table 1). Regardless of the cause, thrombocytopenia can be found in between $7 \%$ and $12 \%$ of pregnant patients ${ }^{3,4}$. Thrombocytopenia is the second most frequent anomaly in a complete blood cell count during pregnancy, after anemia. Approximately $8 \%$ of women can develop mild thrombocytopenia $(100,000 / \mu \mathrm{l}-150,000 / \mu \mathrm{l})$ during pregnancy, from which $65 \%$ will not have a precipitating pathology 5,6 . Nevertheless, in all patients with a platelet count under $100,000 / \mu l$, the cause, which may or may not be linked to pregnancy, ought to be found ${ }^{4,7,8}$ (Table 2).

In general, the most frequent causes of thrombocytopenia during pregnancy are gestational thrombocytopenia (GT) which accounts for $60-75 \%$ of

\section{Correspondence:}

${ }^{*}$ Cesar Homero Gutiérrez-Aguirre

E-mail: hematohu@yahoo.com
Available online: $27-05-2019$

Date of reception: 18-10-2018

Date of acceptance: 15-01-2019

DOI: 10.24875/RMU.19000036
Medicina Universitaria. 2019;21(1):14-18 www.medicinauniversitaria.org

(O) 2019 Universidad Autónoma de Nuevo Leon article under the CC BY-NC-ND license (http://creativecommons.org/licenses/by-nc-nd/4.0/). 
Table 1. Causes of thrombocytopenia according to its etiology

\begin{tabular}{l|l|l}
\hline Decrease in production & Increase in destruction & Other \\
\hline Aplastic anemia & ITP & Splenomegaly \\
HIV & TTP & Hypothermia \\
Myelodysplasia & DIC & Pseudotrombocitopenia \\
Acute leukemias & Vasculitis & Malignant hypertension \\
Chemotherapy & Antiphospholipid syndrome & Massive transfusion \\
Ionizing radiation & Autoimmune diseases & Autoimmune hemolytic anemia \\
Viral infections & HELLP syndrome & \\
Renal disease & Pre-eclampsia & \\
Vitamin B12 deficiency & Heart valves & \\
Folic acid deficiency & Endocarditis & \\
Autoimmune diseases & Hemodialysis &
\end{tabular}

HIV: human immunodeficiency virus, ITP: immune thrombocytopenic purpura, TTP: thrombotic thrombocytopenic purpura, DIC: disseminated intravascular coagulation Adapted from: Kappler S, Ronan-Bentle S, Graham A. Thrombotic microangiopathies (TTP, HUS, and HELLP). Hematol Oncol Clin North Am. 2017;31:1081-103.

Table 2. Causes of thrombocytopenia based on its association with pregnancy

\begin{tabular}{|l|l|}
\hline Associated with pregnancy & Independent of pregnancy \\
\hline $\begin{array}{l}\text { Gestational thrombocytopenia } \\
\text { HELLP syndrome }\end{array}$ & $\begin{array}{l}\text { Congenital } \\
\text { Hereditary thrombocytopenia } \\
\text { Pre-eclampsia }\end{array}$ \\
$\begin{array}{ll}\text { Acquired } \\
\text { autoimmune: ITP, SLE, TTP, } \\
\text { and drug-induced } \\
\text { antiphospholipid syndrome } \\
\text { Fatty liver of pregnancy }\end{array}$ & $\begin{array}{l}\text { Not autoimmune: secondary } \\
\text { to infections, bone marrow } \\
\text { diseases, and malnutrition }\end{array}$ \\
\hline
\end{tabular}

PTI: immune thrombocytopenic purpura, LES: systemic lupus erythematosus, TTP: thrombotic thrombocytopenic purpura.

cases, thrombocytopenia linked to pre-eclampsia/eclampsia/hemolysis, elevated liver enzymes, and low platelet (HELLP) syndrome in $21 \%$ of cases and immune thrombocytopenic purpura (ITP) in $3-10 \%$ of the cases, although the latter is not exclusive to pregnancy ${ }^{9}$. Each one has clinical characteristics which are useful in making a correct differential diagnosis (Table 3).

When we talk about moderate-to-severe thrombocytopenia, ITP is the most frequent cause $(42 \%)$ followed by GT $(9 \%)$ and pre-eclampsia $(2 \%)$, as proven in a recent study ${ }^{10}$.

The diagnostic approach is performed under the context of a pregnant patient with bleeding manifestations on the skin and/or mucous membrane, even though in many of the cases, there are not bleeding manifestations, and the thrombocytopenia is a laboratory finding. It is necessary to conduct a complete blood count and a peripheral blood smear to analyze platelet count and morphology, which will need to be complemented with personal background and family history to guide the etiology of thrombocytopenia ${ }^{11}$. It is necessary to keep in mind that thrombocytopenia found in pregnancy is not always linked to it, as observed in GT and thrombocytopenia linked to pre-eclampsia/HELLP, or to fatty liver during pregnancy, but it could also be a manifestation of other illnesses such as ITP, thrombotic thrombocytopenic purpura, antiphospholipid syndrome, erythematosus lupus, and sepsis, so it is necessary to perform an integral differential diagnosis based on clinical and laboratory data since treatment and prognosis are completely different.

\section{GT}

GT is considered a physiological decrease in platelet count during pregnancy that occurs without complications $^{12}$. Its etiology is not known with precision. However, different mechanisms have been proposed, like plasma dilution caused by an increase in volume, antibody-mediated platelet destruction, or a decrease in platelet production ${ }^{13}$. GT is defined as a number of platelets under $150,000 / \mu l$ in non-complicated pregnancies without any other identifiable causes of thrombocytopenia ${ }^{7}$. It is the most frequent cause of thrombocytopenia in pregnancy, occurring in $5-8 \%$ of all pregnancies ${ }^{3}$. In $75 \%$ of cases, platelet count is between $130,000 / \mu \mathrm{l}$ and $150,000 / \mu \mathrm{l}$; only in $10 \%$ of cases is the count below $100,000 / \mu^{3,8}$. It usually has a favorable prognosis without maternal or fetal complications ${ }^{14}$.

To establish a GT diagnosis, it is necessary to have mild thrombocytopenia, typically in the third trimester of pregnancy, without a history of previous thrombocytopenia and resolution in a week or two after term ${ }^{3,8}$. The need for treatment in these patients has not been proven. A platelet count $>100,000 / \mu l$ is considered safe 
Table 3. Characteristics of thrombocytopenia according to its etiology

\begin{tabular}{|l|l|l|l|}
\hline & $\begin{array}{l}\text { Gestational } \\
\text { thrombocytopenia }\end{array}$ & $\begin{array}{l}\text { Immune thrombocytopenic } \\
\text { purpura }\end{array}$ & Hypertensive pregnancy disorder \\
\hline Trimester of pregnancy & $2^{\text {nd }}$ and $3^{\text {rd }}$ & $1^{\text {st }}$ & $3^{\text {rd }}$ and postpartum \\
\hline Degree of thrombocytopenia & Light & Moderate/severe & Moderate/severe \\
\hline Treatment & None & $\begin{array}{l}\text { Steroids/intravenous } \\
\text { immunoglobulin }\end{array}$ & Termination of the pregnancy \\
\hline
\end{tabular}

to apply spinal anesthesia ${ }^{8}$, and some authors even reported a count between $50,000 / \mu \mathrm{l}$ and $80,000 / \mu \mathrm{l}$ as a safe number ${ }^{15}$. A study conducted in 1993 that included 756 patients with GT showed that none of the patients had a hemorrhagic complication, and none of the newborns had platelet numbers under $100,000 / \mu \mathrm{l}$ or a hemorrhagic complication ${ }^{16}$.

In some cases, it may be difficult to differentiate GT from ITP due to the fact that in GT, thrombocytopenia may occasionally be detected in the first trimester and be lower than 100,000/ $\mathrm{\mu l}$. In these patients, the behavior of thrombocytopenia ought to be monitored during pregnancy and postpartum evolution ${ }^{17}$.

\section{Immune thrombocytopenic purpura}

In chronic IPT, thrombocytopenia results from a combination of two mechanisms, accelerated platelet destruction and an insufficient compensatory production in the bone marrow. This disease is caused by the formation of IgG antibodies against the plasma membrane glycoproteins. A platelet count under 100,000/ul during the first trimester of pregnancy with a progressive decrease is indicative of ITP ${ }^{3}$. It is important to establish a diagnosis and differentiate it from other types of thrombocytopenia like GT since ITP does elevate the risk of maternal and fetal bleeding. Since the IgG antibodies have the ability to cross the placenta, the product may present thrombocytopenia under $100,000 / \mu \mathrm{l}$ in $15-50 \%$ of cases, under $50,000 / \mu \mathrm{l}$ in $8-30 \%$ of cases, and under $20,000 / \mu$ in $1-8 \%$ of cas$\mathrm{es}^{3,18}$, as well as presenting an intracranial hemorrhage in up to $2 \%{ }^{8,18}$.

The most important factor in establishing a diagnosis is a background of thrombocytopenia or a history of bleeding (petechiae, ecchymosis, epitaxy, and gingivorrhagia) before pregnancy or during the $1^{\text {st }}$ week of gestation; even though in many cases, the ITP diagnosis is already known before pregnancy.

Patients who already have a chronic ITP diagnosis and are in complete remission ought to be closely monitored, considering that there could be relapsed with severe bleeding ${ }^{19}$. Women without abnormal bleeding or a platelet count $>30,000 / \mu$ l have not been proven to require any treatment, especially during the $1^{\text {st }}$ week of gestation. In case they require treatment, the first line is oral steroids and intravenous immunoglobulin (IgIV) ${ }^{20}$. The American Society of Hematology recommends administrating treatment in cases of severe thrombocytopenia or thrombocytopenia with the presence of abnormal bleeding ${ }^{21}$. Recommendations suggest beginning steroids at a dose of $1 \mathrm{mg} / \mathrm{kg}$ of prednisone or prednisolone until reaching a safe number of platelets $(30,000 / \mu \mathrm{l})$. Nevertheless, it is necessary to remain alert since the frequency of adverse effects caused by steroids is more significant during pregnancy. When the expected response with steroids is not obtained, or the physician prefers to avoid its adverse effects, a dose of $2 \mathrm{~g} / \mathrm{kg} /$ day of IgIV can be administered over 2-5 days, but its effects are usually transitory, lasting from 1 to 4 weeks. This option is of great help when the term of the pregnancy is close to avoid obstetric bleeding $^{8}$. Between $31 \%$ and $49 \%$ of patients with ITP need to receive treatment with glucocorticoids or IgIV during or after pregnancy 22,23 .

Splenectomy should be reserved for severe refractory ITP and ought to be performed during the second trimester of pregnancy ${ }^{24,25}$.

In a study conducted recently, we were able to observe that postpartum hemorrhage complications occur with more frequency in women with a diagnosis of ITP than in women who course a normal pregnancy. Furthermore, postpartum hemorrhage was greater in women who required treatment for ITP than those who did not. On the other hand, the incidence of neonatal thrombocytopenia in children of mothers diagnosed with ITP was $12 \%{ }^{26}$. In a different study from 1993 , results show that those newborns who suffered morbidity and mortality as a result of thrombocytopenia were products of mothers with a diagnosis of ITP ${ }^{16}$. Due to a greater incidence of thrombocytopenia in newborns of mothers with an ITP diagnosis, routinely measuring the platelet count on the umbilical cord is 
recommended, week after week, and if it is lower than $50,000 / \mu \mathrm{l}$, a transcranial ultrasound is suggested, and if the count is under $20,000 / \mu l$ or there is evidence of bleeding, an IgIV or steroids should be administered ${ }^{3}$.

\section{Thrombocytopenia linked to hypertensive pregnancy disorder, pre-eclampsia, and HELLP syndrome}

Pre-eclampsia is characterized by the presence of high blood pressure, proteinuria, and edema in the extremities. It occurs in 5-8\% in the world's population ${ }^{27}$ and remains as one of the main causes of maternal and fetal morbidity/mortality, even in developed countries ${ }^{28}$. It occurs more frequently in women who are in their first pregnancy, women who are under 20 years of age or older than 30 , with obesity, chronic hypertension, and a history of resistance to insulin ${ }^{13}$.

The HELLP syndrome is a pregnancy complication which compromises the life of both the mother and the fetus. It is usually observed in patients with severe pre-eclampsia. However, it may also occur without it. First described in 1982 by Weinstein, who called it the HELLP syndrome as an acronym of hemolysis $(\mathrm{H})$, elevated liver enzymes (EL) and low platelet count (LP) ${ }^{29}$. It affects between 0.5 and $0.9 \%$ of all pregnancies and up to $20 \%$ of complicated pregnancies with severe pre-eclampsia ${ }^{30}$. Of the women who course their pregnancy with pre-eclampsia, between $15 \%$ and $50 \%$ develop thrombocytopenia, while those patients who develop HELLP syndrome, on top of a platelet count of $<150,000 / \mu l$, generally also present elevation of hepatic enzymes and the presence of microangiopathic hemolytic anemia ${ }^{3,31}$.

Definite treatment for these illnesses is the termination of pregnancy ${ }^{13}$. Before 34 weeks of gestation, support treatment is provided to stabilize patients and allow pulmonary maturation of the product using two doses of betamethasone. In those patients in which a C-section is required, transfusions of platelet concentrates can be used to reach a safe number immediately before the procedure, even though the half-life of transfused platelets is diminished in women with these illnesses ${ }^{31}$.

Reports suggest the possibility of performing a fresh frozen plasma transfusion to treat those patients complicated with disseminated intravascular coagulation ${ }^{32}$, and steroids for patients with prolonged thrombocytopenia, an increase in lactic dehydrogenase and postpartum multiorgan dysfunction ${ }^{33}$.

ITP and hypertensive pregnancy disorders are the main maternal risk factor for the development of neonatal thrombocytopenia ${ }^{34}$.

\section{Conclusion}

Thrombocytopenia during pregnancy results from diverse causes, which may or may not be linked to pregnancy. It is important to establish a proper diagnosis to administer timely treatment, improving maternal and neonatal prognosis. In most cases, GT does not require treatment and has a benign evolution for the mother and the baby; on the other hand, ITP usually courses with more severe thrombocytopenia, requiring treatment in up to $49 \%$ of patients, and is linked to a greater morbidity-mortality index in both the mother and the fetus. Thrombocytopenia caused by hypertensive pregnancy disorders requires urgent medical attention; its definite treatment is the termination of the pregnancy.

\section{Conflicts of interest}

The authors declare no conflicts of interest.

\section{Financing}

The preparation of this article did not require financing.

\section{Ethical disclosures}

Protection of human and animal subjects. The authors declare that no experiments were performed on humans or animals for this study.

Confidentiality of data. The authors declare that no patient data appear in this article.

Right to privacy and informed consent. The authors declare that no patient data appear in this article.

\section{References}

1. Kappler S, Ronan-Bentle S, Graham A. Thrombotic microangiopathies (TTP, HUS, HELLP). Hematol Oncol Clin North Am. 2017;31:1081-103.

2. Shantsila E, Lip GY, Chong BH. Heparin-induced thrombocytopenia. A contemporary clinical approach to diagnosis and management. Chest. 2009;135:1651-64.

3. Bergmann F, Rath W. The differential diagnosis of thrombocytopenia in pregnancy. Dtsch Arztebl Int. 2015;112:795-802.

4. Goldman BG, Hehir MP, Yambasu S, O'Donnell EM. The presentation and management of platelet disorders in pregnancy. Eur $\mathrm{J}$ Haematol. 2018;100:560-6

5. Matthews JH, Benjamin S, Gill DS, Smith NA. Pregnancy-associated thrombocytopenia: definition, incidence and natural history. Acta Haematol. $1990 ; 84: 24-9$

6. Burrows RF, Kelton JG. Thrombocytopenia at delivery: a prospective survey of 6715 deliveries. Am J Obstet Gynecol. 1990;162:731-4.

7. Reese JA, Peck JD, Mclntosh JJ, et al. Platelet counts during pregnancy. N Engl J Med. 2018;379:32-43.

8. Bockenstedt PL. Thrombocytopenia in pregnancy. Hematol Oncol Clin North Am. 2011;25:293-310, 7-8.

9. Jodkowska A, Martynowicz H, Kaczmarek-Wdowiak B, Mazur G. Thrombocytopenia in pregnancy pathogenesis and diagnostic approach. Postepy Hig Med Dosw (Online). 2015;69:1215-21. 
10. Kim BJ, Kim HS, Kim JH, Lee KY. Moderate to severe thrombocytopenia during pregnancy: a single institutional experience. Indian J Hemato Blood Transfus. 2017;33:581-5.

11. Fogerty $A E$. Thrombocytopenia in pregnancy: mechanisms and management. Transfus Med Rev. 2018;32:225-9.

12. Boehlen F, Hohlfeld P, Extermann P, Perneger TV, de Moerloose P. Platelet count at term pregnancy: a reappraisal of the threshold. Obstet Gynecol 2000;95:29-33.

13. Palta A, Dhiman P. Thrombocytopenia in pregnancy. J Obstet Gynaecol. 2016;36:146-52.

14. Wang $X, X u Y$, Luo $W$, et al., Thrombocytopenia in pregnancy with different diagnoses: differential clinical features, treatments, and outcomes. Medicine (Baltimore). 2017;96:e7561.

15. Tanaka M, Balki M, McLeod A, Carvalho JC. Regional anesthesia and non-preeclamptic thrombocytopenia: time to re-think the safe platele count. Rev Bras Anestesiol. 2009;59:142-53.

16. Burrows RF, Kelton JG. Fetal thrombocytopenia and its relation to maternal thrombocytopenia. N Engl J Med. 1993;329:1463-6.

17. Kasai J, Aoki S, Kamiya N, et al. Clinical features of gestational thrombocytopenia difficult to differentiate from immune thrombocytopenia diagnosed during pregnancy. J Obstet Gynaecol Res. 2015;41:44-9.

18. Provan D, Stasi R, Newland AC, et al. International consensus report on the investigation and management of primary immune thrombocytopenia. Blood. 2010;115:168-86

19. Comont T, Moulis G, Parant O, Derumeaux H, Rauzy OB. Effect of pregnancy in women with a history of primary immune thrombocytopenia considered as cured. Eur J Intern Med. 2017;46:e15-e16.

20. Gernsheimer T, James AH, Stasi R. How I treat thrombocytopenia in pregnancy. Blood. 2013;121:38-47.

21. George JN, Woolf SH, Raskob GE, et al. Idiopathic thrombocytopenic purpura: a practice guideline developed by explicit methods for the American society of hematology. Blood. 1996;88:3-40.

22. Loustau V, Debouverie O, Canoui-Poitrine F, et al. Effect of pregnancy on the course of immune thrombocytopenia: a retrospective study of 118 pregnancies in 82 women. $\mathrm{Br} \mathrm{J}$ Haematol. 2014;166: 929-35.

23. Webert KE, Mittal R, Sigouin C, Heddle NM, Kelton JG. A retrospective 11-year analysis of obstetric patients with idiopathic thrombocytopenic purpura. Blood 2003;102:4306-11.

24. Verdy $\mathrm{E}$, Bessous V, Dreyfus $\mathrm{M}$, et al. Longitudinal analysis of platelet count and volume in normal pregnancy. Thromb Haemost. 1997:77:806-7.

25. Griffiths J, Sia W, Shapiro AM, Tataryn I, Turner AR. Laparoscopic splenectomy for the treatment of refractory immune thrombocytopenia in pregnancy. J Obstet Gynaecol Can. 2005;27:771-4.

26. Gilmore KS, McLintock C. Maternal and fetal outcomes of primary immune thrombocytopenia during pregnancy: a retrospective study. Obstet Med. 2018;11:12-6.

27. Jim B, Karumanchi SA. Preeclampsia: pathogenesis, prevention, and long-term complications. Semin Nephrol. 2017;37:386-97.

28. Dymara-Konopka W, Laskowska M, Oleszczuk J. Preeclampsia current management and future approach. Curr Pharm Biotechnol. 2018;19: 786-96.

29. Weinstein L. Syndrome of hemolysis, elevated liver enzymes, and low platelet count: a severe consequence of hypertension in pregnancy. Am J Obstet Gynecol. 1982;142:159-67.

30. Haram K, Svendsen E, Abildgaard U. The HELLP syndrome: clinical issues and management. A review. BMC Pregnancy Childbirth. 2009;9:8.

31. McCrae KR. Thrombocytopenia in pregnancy: differential diagnosis, pathogenesis, and management. Blood Rev. 2003;17:7-14.

32. McCrae KR, Samuels P, Schreiber AD. Pregnancy-associated thrombocytopenia: pathogenesis and management. Blood. 1992;80:2697-714.

33. Martin JN Jr., Perry KG Jr., Blake PG, et al. Better maternal outcomes are achieved with dexamethasone therapy for postpartum HELLP (hemolysis, elevated liver enzymes, and thrombocytopenia) syndrome. Am J Obstet Gynecol. 1997;177:1011-7.

34. Resch E, Hinkas O, Urlesberger B, Resch B. Neonatal thrombocytopenia-causes and outcomes following platelet transfusions. Eur J Pediatr. 2018;177:1045-52. 